\title{
Monomelic Atrophy
}

\author{
J. Oryema, P. Ashby and S. Spiegel
}

\begin{abstract}
Weakness of distal muscles of one upper limb which progresses over 1 year and then appears to arrest ("monomelic amyotrophy") has been reported mainly in Japan and India. We report 5 cases of a similar syndrome occurring in Canada. In our cases the wasting affected the forearm muscles of one upper limb (sparing brachioradialis and extensor carpi radialis). There was minimal wasting and electromyographic changes in the opposite upper limb. The CT myelogram showed unilateral wasting of the cervical cord.

RÉSUMÉ: Atrophie monomélique Une faiblesse musculaire distale au niveau d'un membre supérieur, qui évolue sur une période d'un an et qui semble ensuite arrêter de progresser ("amyotrophie monomélique") a été rapportée surtout au Japon et aux Indes. Nous rapportons 5 cas d'un syndrome similaire survenus au Canada. Chez nos cas, l'atrophie atteignait les muscles de l'avant-bras d'un membre supérieur (épargnant le long supinateur et le radial). Il y avait peu d'atrophie et de changements électromyographiques dans le membre supérieur opposé. Le myélogramme par CT a montré une atrophie unilatérale de la moelle épinière cervicale.
\end{abstract}

Can. J. Neurol. Sci. 1990; 17:124-130

Hirayama et al ${ }^{1}$ were the first to describe a condition in which there was progressive wasting and weakness of the distal muscles of one upper limb which became arrested after $1-2$ years. They called it "juvenile muscular atrophy of unilateral upper extremity" but it is also known as "monomelic amyotrophy", 3 "juvenile type of distal and segmental muscle atrophy of the upper extremities"4 and "benign focal amyotrophy".5,6

The clinical features of the approximately 150 cases reported in Japan have been summarized by Hirayama et al. ${ }^{7}$

1. The condition occurs in young men (15-25 years). 2 . The wasting and weakness affect mainly the hand and forearm muscles sparing the brachioradialis. 3. It comes on insidiously, progresses for $1-2$ years and then remains stationary. 4 . It is usually unilateral (although EMG examination may show subclinical abnormalities on the opposite side) but sometimes bilateral. 5. The weakness may be exaggerated in the cold. There is often a tremor of the affected fingers. 6 . There are no sensory abnormalities or long tract signs. 7. Nerve conduction velocities are normal. Electromyography shows chronic neurogenic changes in the affected muscles. 8. Contrast studies may show atrophy of the lower cervical cord.

A similar condition involving proximal muscles of one upper $\operatorname{limb}^{3,6,8}$ or of the calf and thigh muscles of one lower limb 3,9 has also been described.

About 150 cases have been reported in Japan, 1.2,4.7.10 47 in India, ${ }^{3,11} 19$ in Malaya, ${ }^{12}$ six in Australia, ${ }^{13}$ six, some atypical, in Holland, ${ }^{14,15}$ one in Denmark, ${ }^{16}$ one in Israel ${ }^{8}$ and two, rather atypical cases, in North America (one involving the muscles of the lower $\operatorname{limb}^{9}$ and one involving the proximal muscles of one upper $\operatorname{limb}^{6}$ ).
It is not known whether the condition is less frequent in North America or is simply not reported. We report 5 typical cases attending a routine clinical EMG laboratory over a 2 year period suggesting that the condition may be just as common in North America.

\section{METHODS}

A full neurological examination was carried out on all patients. Muscle strength was graded on the MRC scale. Vibration threshold at the tips of the fingers and toes was measured using a Bio-Thesiometer (Biomedical Instruments Co, Newberry, Ohio). Light touch threshold was estimated using an Aesthesiometer (a flexible hair of variable length) on the dorsum of the fingers and toes just proximal to the nail bed. Motor and sensory nerve conduction studies were carried out in the conventional manner. ${ }^{17}$ Sympathetic skin responses were recorded from hand and foot using surface electrodes over the palmar/plantar and dorsal surfaces in response to a stimulus of $30 \mathrm{~mA}$ to the median nerve. 18 Electromyography was carried out using concentric needle electrodes. Fibrillation was scored $0-4+$, fasciculations $0-4+$. Single fibre $\mathrm{EMG}^{19}$ was used to measure "jitter" and to estimate fibre density.

A CT myelogram was performed using a lumbar puncture to instill $15 \mathrm{ml}$ of Iohoxol $240 \mathrm{mg} / \mathrm{ml}$ concentration. A CT scan was performed after the myelogram from $\mathrm{C} 4$ to $\mathrm{C} 7$ with $3 \mathrm{~mm}$ intervals and slice thickness. A GE 9800 CAT scan was used.

MRI scans were carried out using a 1.5 Tesla GE Sigma MR system. Saggital projections with $\mathrm{TI}$ weighting $(\mathrm{TE}=20, \mathrm{TR}=$ 600 ) were obtained in all patients. Axial T1 weighted images

From the EMG Department, Toronto Western Hospital, Toronto

Received September 15, 1989. Accepted in final form December 22, 1989

Reprint requests to: Dr. Peter Ashby, Toronto Western Hospital, 399 Bathurst Street, Toronto, Ontario, Canada M5T 2S8 


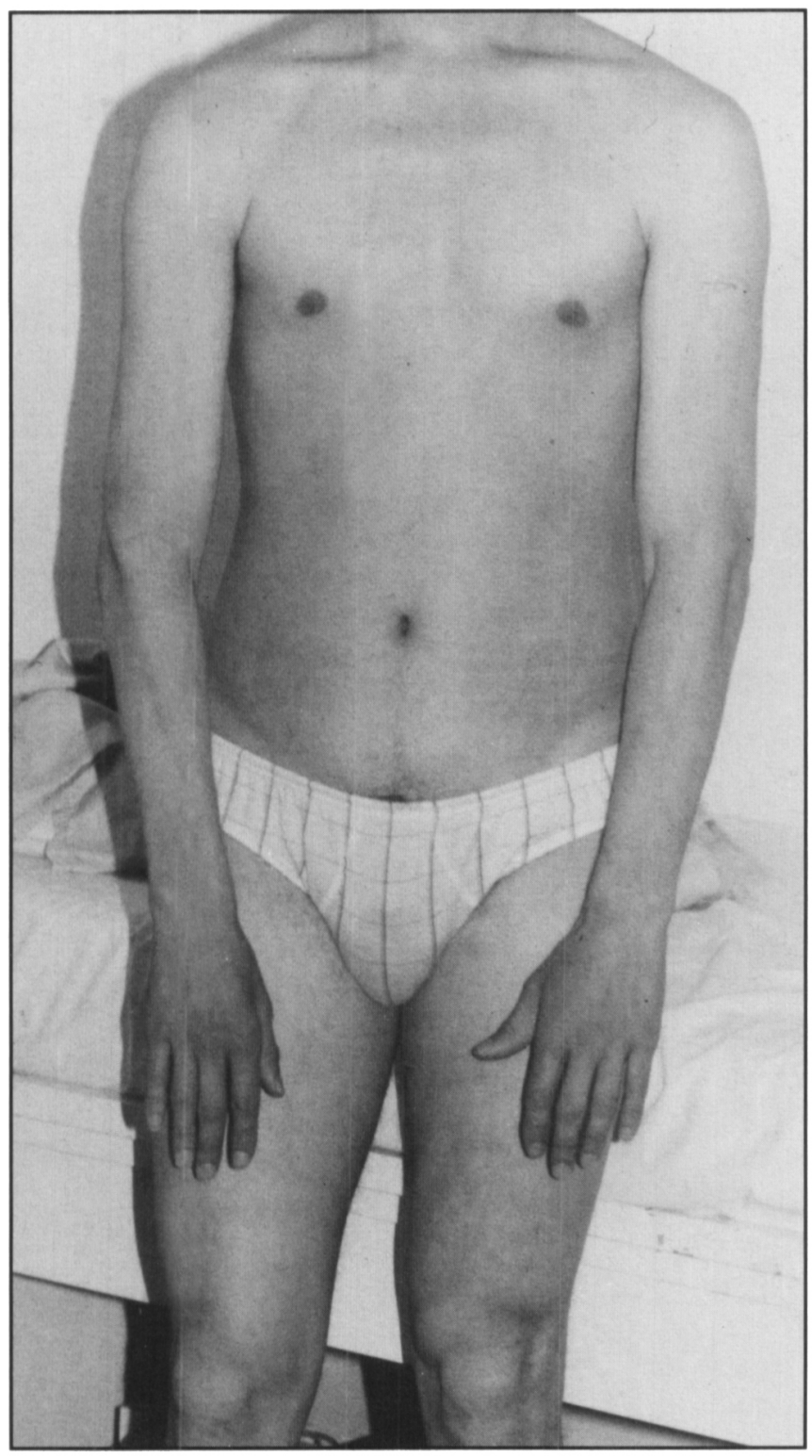

Figure I - Case I (NG) There is wasting, on the right. of the small muscles of the hand and of the forearm muscles sparing brachioradialis. On the left there is minimal wasting of these muscles also.

were obtained in 3 of the patients. Sagittal and axial T2 weighted $(\mathrm{TR}=2800, \mathrm{TE}=70)$ images were obtained in 2 patients.

\section{Case Histories}

\section{Case 1 (NG)}

This 22 year old right handed caucasian male first noticed wasting and weakness of his right hand and forearm in 1985. He had difficulty writing and had noted twitching and cramps in the weak muscles. By 1986 the weakness of the right forearm had progressed and there was wasting of distal muscles of the left forearm as well. By 1987 his condition had stabilized and there was no further progression. There were no sensory symptoms.

On examination there was profound wasting (Figure 1) and weakness (Table 1) of the right distal forearm and hand muscles sparing brachioradialis. There was some weakness of the right triceps. There was also slight wasting of the left distal forearm, weakness of the left first dorsal interosseous, and a questionable asymmetry of the vastus medi- alis (slightly smaller on the right).

The reflexes were normal except that the right triceps jerk was depressed and the right finger jerk was absent. The plantar reflexes were flexor. There was no sensory loss.

\section{Electrophysiology}

The motor nerve conduction velocities, distal latencies, muscle compound action potential amplitudes and $F$ wave latencies were normal bilaterally (Table 2). Electromyography (Table 1) showed chronic neurogenic changes which were most marked in the hand muscles of both upper limbs but also involved the forearm muscles on the right (e.g., 5 of 20 single fibre pairs in the right extensor digitorum communis (EDC) had jitter $>55 \mathrm{msec}$ ). There were minor, but definite, abnormalities in more proximal muscles on the right (e.g., increased fibre density in the right deltoid to 1.75 , (normal $<1.68$ ) and right biceps to 2.1 , (normal $<1.43)$ ). Similar mild neurogenic changes were also seen in clinically unaffected muscles on the left (e.g., increased fibre density in the left EDC to 2.6 (normal $<1.79$ )). There were no abnormalities in the lower limb muscles tested (e.g., fibre density in the right vastus medials was 1.7 (normal <1.79)).

\section{Other Investigations}

The CT myelogram showed flattening of the cord on the right side from $\mathrm{C5}$ to $\mathrm{C} 7$ (Figure 2). No additional abnormality of the cord was demonstrated on the 24 hour delayed scan. MRI scan showed loss of the normal cervical enlargement. Instead the cord appeared to be atrophied opposite the $\mathrm{C} 6,7, \mathrm{Tl}$ vertebrae (Figure $3 \mathrm{a}$ ) and the CSF space appeared to be increased at these levels (Figure $3 \mathrm{~b}$ ). The CSF protein was normal at $0.35 \mathrm{~g} / \mathrm{L}$. Other laboratory investigations (see below) were normal.

\section{Course}

His clinical picture has remained unchanged from 1987 to 1989.

\section{Case 2 (ID)}

This 16 year old right handed caucasian male was a grade 11 student. He had fallen on his outstretched right hand in the summer of 1986 but had not sustained any obvious injury and had been subsequently symptomless. He began to notice wasting and weakness of his right hand in the fall of 1986 with difficulty playing the guitar, doing up buttons, and cutting food. The weakness progressed for about one year and then remained stable. There were no sensory symptoms.

On examination the clinical abnormalities were restricted to the right forearm and hand (Table 1). There was wasting of the distal mus-

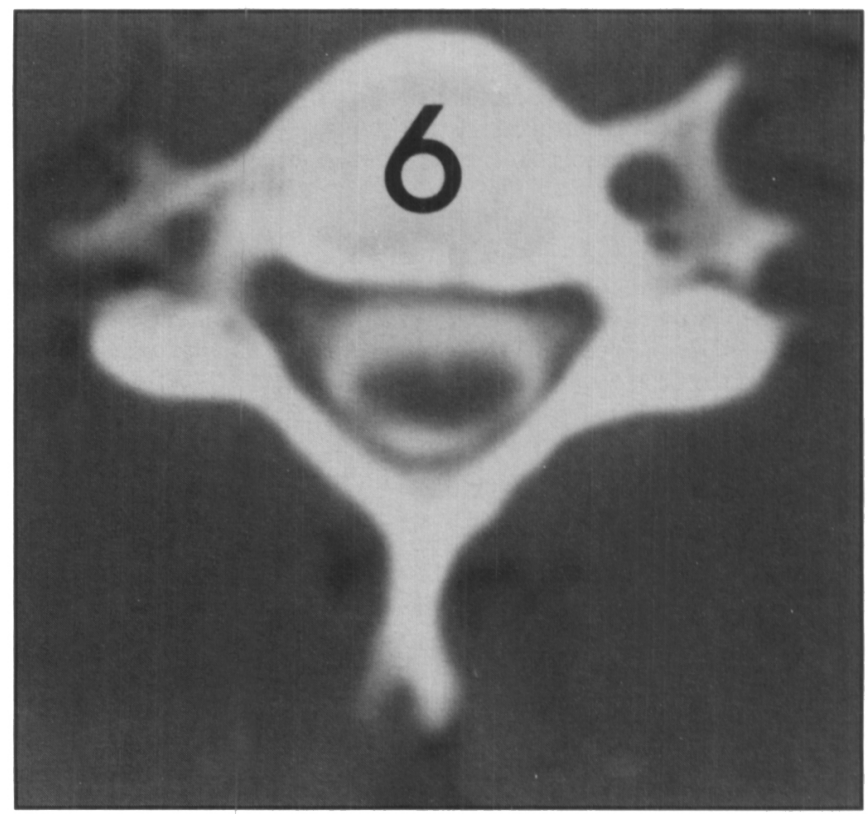

Figure 2-Case I (NG) CT myelogram at C6. Note the atrophy of the right side of the cord (left side of figure). 


\begin{tabular}{|c|c|c|c|c|c|c|c|c|c|c|}
\hline & \multicolumn{2}{|c|}{ NG } & \multicolumn{2}{|c|}{ ID } & \multicolumn{2}{|l|}{ YK } & \multicolumn{2}{|l|}{ ML } & \multicolumn{2}{|c|}{$\mathbf{M M}$} \\
\hline & $\mathbf{R}$ & $\mathbf{L}$ & $\mathbf{R}$ & $\mathbf{L}$ & $\mathbf{R}$ & $\mathbf{L}$ & $\mathbf{R}$ & $\mathbf{L}$ & $\mathbf{R}$ & $\mathbf{L}$ \\
\hline Deltoid & $\begin{array}{l}5 \\
\text { OOL }\end{array}$ & $\begin{array}{l}5 \\
\text { OON }\end{array}$ & 5 & 5 & $\begin{array}{l}5 \\
\text { OOR }\end{array}$ & 5 & 5 & 5 & $\begin{array}{l}5 \\
\text { OON }\end{array}$ & $\begin{array}{l}5 \\
\text { OON }\end{array}$ \\
\hline Biceps & $\begin{array}{l}5 \\
\text { OOLR }\end{array}$ & 5 & $\begin{array}{l}5 \\
\text { OON }\end{array}$ & 5 & $\begin{array}{l}5 \\
\text { OOR }\end{array}$ & 5 & 5 & 5 & 5 & 5 \\
\hline Triceps & 4 & $\begin{array}{l}5 \\
\text { OOR }\end{array}$ & $\begin{array}{l}4+ \\
\text { OOLR }\end{array}$ & 5 & $\begin{array}{l}4 \\
30 \mathrm{LR}\end{array}$ & 5 & $\begin{array}{l}5 \\
\text { OON }\end{array}$ & 5 & $\begin{array}{l}5- \\
\text { IOLR }\end{array}$ & $\begin{array}{l}5 \\
\text { OlLR }\end{array}$ \\
\hline EDC & $\begin{array}{l}3 \\
\text { OOLR }\end{array}$ & 5 & 3 & $\begin{array}{l}5 \\
\text { OON }\end{array}$ & $\begin{array}{l}0 \\
300\end{array}$ & $\begin{array}{l}5 \\
\text { LR }\end{array}$ & $\begin{array}{l}3 \\
\text { OOLR }\end{array}$ & 3 & $5-$ & 5 \\
\hline $\mathrm{FCU}$ & 3 & 5 & 3 & $\begin{array}{l}5 \\
21 L R\end{array}$ & $\begin{array}{l}4 \\
\text { OOLR }\end{array}$ & 5 & 3 & 4 & 4 & 5 \\
\hline FDP & 3 & 5 & 3 & 5 & $5-$ & 5 & 3 & 3 & 4 & 5 \\
\hline APB & $\begin{array}{l}3 \\
\text { OOLR }\end{array}$ & 5 & 2 & $\begin{array}{l}5 \\
\text { OILR }\end{array}$ & $\begin{array}{l}3 \\
\text { OILR }\end{array}$ & 5 & 3 & 3 & $\begin{array}{l}3 \\
12 \mathrm{LR}\end{array}$ & 5 \\
\hline IDI & $\begin{array}{l}3 \\
\text { OILR }\end{array}$ & $\begin{array}{l}4 \\
\text { O3LR }\end{array}$ & $\begin{array}{l}2 \\
20 \mathrm{LR}\end{array}$ & $\begin{array}{l}5 \\
11 \mathrm{LR}\end{array}$ & $\begin{array}{l}2 \\
\text { OILR }\end{array}$ & 5 & $\begin{array}{l}3 \\
21 \mathrm{LR}\end{array}$ & 3 & $\begin{array}{l}3 \\
\text { IILR }\end{array}$ & $\begin{array}{l}5 \\
\text { O1LR }\end{array}$ \\
\hline $\mathrm{AD} M$ & & & $\begin{array}{l}2 \\
20 \mathrm{LR}\end{array}$ & 5 & & & & & & \\
\hline
\end{tabular}

$\mathrm{R}=\mathrm{Right}, \mathrm{L}=$ Left. The strength of each muscle is indicated by the MRC scale $0-5$ on the top row. The EMG findings are indicated on the lower row. The first digit indicates the presence or absence of fibrillation (0-4). Second digit indicates the presence or absence of fasiculation (0-4). The subsequent letters indicate the characteristics of the voluntary EMG: $N=$ Normal, $L=$ enlarged motor unit action potentials, $R=$ reduced number of motor units. $\mathrm{O}=$ no voluntary activity.

Note that the weakness is mainly distal and, except for ML, mainly unilateral although EMG abnormalities are detected on the clinically "uninvolved" side. ADM: Abductor digiti quniti, APB: Abductor pollicis brevis, EDC: Extensor digitorum communis, FCU: Flexor carpi ulnaris, FDP: flexor digitorum profundus, IDI: first dorsal interosseous.

cles of the right forearm and hand and weakness of the small hand muscles, the wrist and finger flexors, extensor digitorum communis, extensor carpi radialis, and, to a lesser extent, the right triceps. Reflexes were $2+$ symmetrical and the plantar reflexes flexor. The sensory examination was entirely normal.

\section{Electrophysiology}

The nerve conduction studies are shown in Table 2. The electromyographic abnormalities are shown in Table 1. No abnormalities were detected in the cervical or thoracic paraspinal muscles.

\section{Other Investigations}

The CT myelogram showed atrophy of the right side of the cord from $\mathrm{C} 5$ to $\mathrm{C} 7$ vertebrae (Figure 4). This could just be discerned on the axial MRI. There was loss of the normal cervical enlargement on the saggital MRI scan. The CSF and other laboratory results were normal except that the CPK was raised to 328 (normal range 24-205 u/L).

\section{Course} 1989.

There has been no change in his clinical condition from 1988 to

\section{Case 3 (YK)}

This 20 year old right handed Chinese male immigrated to Canada from China in 1982. Prior to coming to Canada he noted painless weakness of movements of his right index finger and over one year the whole right hand and forearm became weak and wasted. He stopped Kung Fu exercises because of his hand weakness. There were no sensory symptoms. On examination there was wasting of the right forearm and hand muscles but with striking preservation of brachioradialis and extensor carpi radialis (Figure 5). There was weakness, on the right only, of the triceps, flexor carpis ulnaris, wrist extensors and flexors and all of the intrinsic hand muscles (Table 1).
Table 2: Results of Median and Ulnar Motor Nerve Conduction Studies

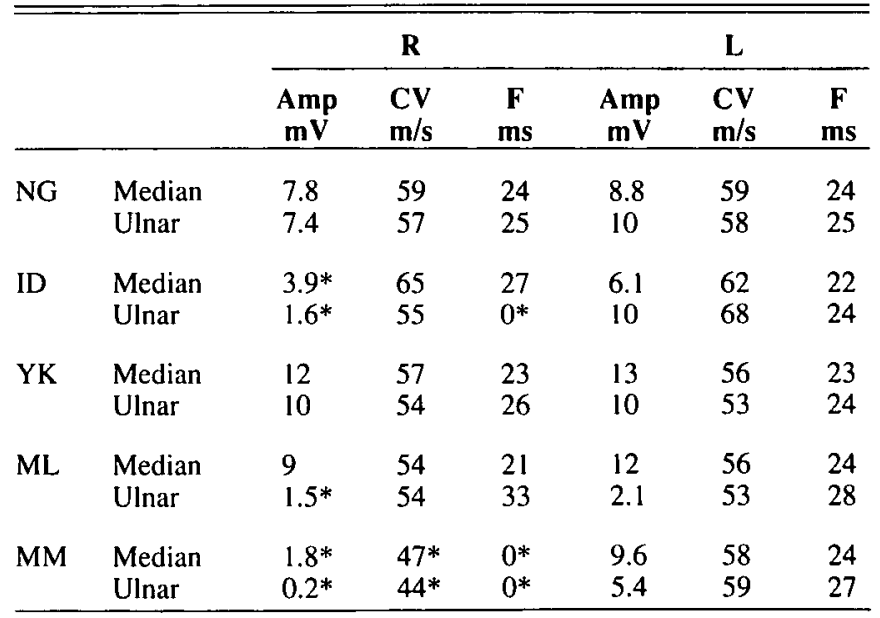

Amp indicates the amplitude in $\mathrm{mV}$ of the compound muscle action potential evoked from the abductor pollicis brevis by stimulation of the median nerve at the wrist or from the abductor digiti minimi by stimulation of the ulnar nerve at the wrist. CV refers to the conduction velocity in metres/sec from above the elbow to wrist. $F$ refers to the $F$ wave latency from wrist (less the distal latency). $O=$ unobtainable. The abnormal findings are indicated by an asterisk. Note that patients NG and $Y K$ had muscle compound action potentials within the normal range in spite of clinical weakness and wasting. 
The right triceps reflex was unobtainable but the left was $2+$. Biceps and brachioradialis reflexes were $1+$ bilaterally. The lower limb reflexes were normal and the plantar reflexes were flexor. There was no sensory loss.

\section{Electrophysiology}

Nerve conduction studies were normal (Table 2). The electromyographic abnormalities are shown in Table 1. Fibre density was increased in the left extensor digitorum communis $(2.8$, normal $1.79)$ and right deltoid $(1.9$, normal $<1.68)$.

\section{Other investigations}

MRI showed slight atrophy and flattening of the cord opposite the C6 vertebrae. Other laboratory results were normal.

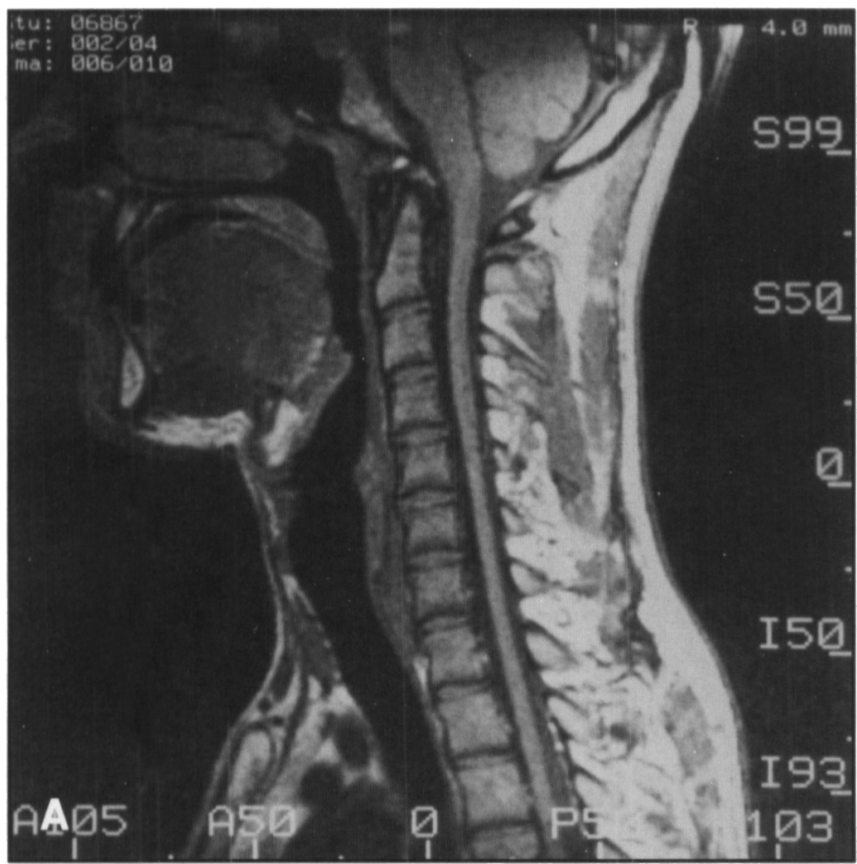

Figure 3 - Case I (NG) MRI scan. a) TI weighted sagittal; b) T2 weighted sagittal. Note the atrophy of the cord opposite vertebral bodies of $\mathrm{C6}, \mathrm{C7}, \mathrm{Tl}$

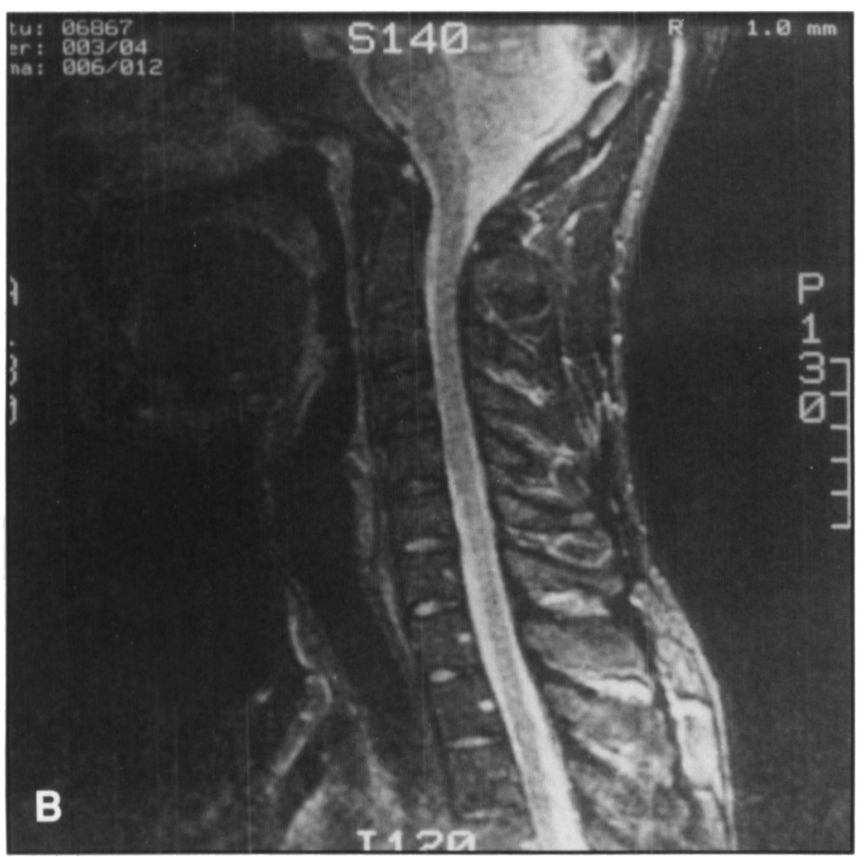

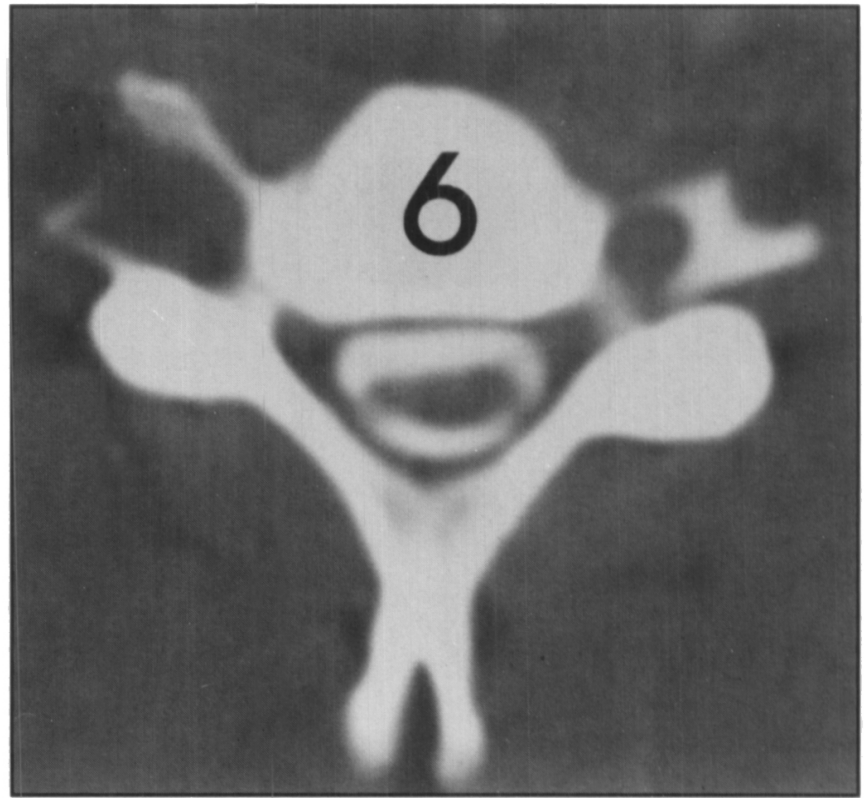

Figure 4-Case 2 (ID) CT myelogram. Note the atrophy of the right side of the cord (left side of the figure).

\section{Course}

The clinical findings have been stable from 1985 to 1989.

\section{Case 4 (ML)}

This 22 year old right handed caucasian had been a well controlled insulin-dependent diabetic since the age of nine. He first noticed painless weakness of his right hand grip when playing tennis in 1983 and then became aware of slowly progressive weakness of both hands and forearm muscles, right more than left, over the next three years. His condition remained stable for the next two years. There were no sensory symptoms.

On examination there was weakness and wasting of the forearm and hand muscles bilaterally with the wasting most marked on the right (see Table 1). The biceps jerks were normal (2+), the triceps jerks depressed $(1+)$ and the finger jerks absent. The lower limb muscle bulk, power and reflexes were normal and the plantar reflexes flexor.

\section{Electrophysiology}

Normal sensory action potentials were obtained from the median. ulnar and sural nerves with normal distal latencies bilaterally. Normal sympathetic skin responses were present in both hands. The muscle action potentials evoked by stimulating the ulnar nerve were reduced bilaterally (Table 2 ). Peroneal motor nerve conduction velocities and muscle compound action potentials were entirely normal.

$F$ wave latencies were normal except for the right ulnar nerve. Needle electrode examination showed a reduction in the number of motor units and large amplitude motor unit action potentials in the right first dorsal interosseous and extensor digitorum communis. The right triceps was normal. Fibre density in the right deltoid was 1.6 (normal $<1.68$ ).

\section{Other Investigations}

A CT myelogram showed mild focal atrophy of right side of cord at C6-7. MRI scan showed atrophy of the spinal cord opposite the C6, C7, and $\mathrm{T} 1$ vertebrae. The other laboratory investigations were normal.

\section{Course}

The clinical findings have been stable from 1986 to 1989.

\section{Case 5 (MM)}

This 20 year old right handed caucasian male factory worker developed painless wasting and weakness of the right hand beginning in 1985. He had difficulty writing, cutting food and doing up buttons. The 


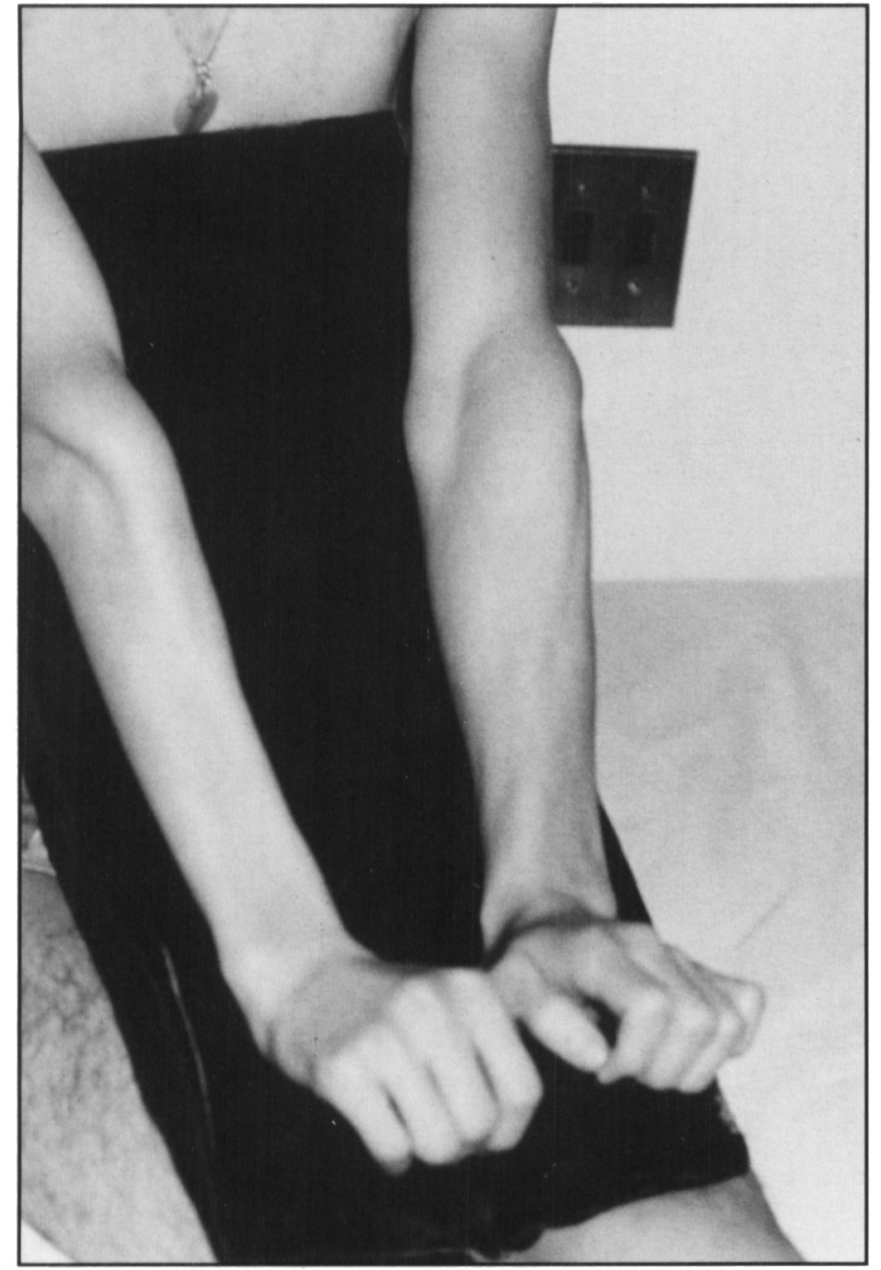

Figure 5-Case $3(Y K)$ Note the wasting of the forearm muscles on the right with sparing of the brachioradialis and extensor carpi radialis.

weakness progressed slowly over one year and then remained unchanged. There were no sensory symptoms.

The clinical abnormalities were restricted to the right upper limb. There was weakness of the small hand muscles, the finger flexors, and extensors, flexor carpi ulnaris and minimal weakness of the right triceps (see Table 1).

The biceps and triceps reflexes were $2+$ and symmetrical. The lower limb reflexes were normal and the plantar reflexes were flexor. The sensory examination was entirely normal.

\section{Electrophysiology}

The results of nerve conduction studies are shown in Table 2. The electromyographic abnormalities are shown in Table 1. No abnormalities were detected in the cervical paraspinal muscles (C7) or in the lower limbs.

\section{Other Investigations}

A CT myelogram showed atrophy of the right side of the cord. MRI scan of the cervical spine (not best quality) did not clearly show atrophy. The other laboratory investigations were normal.

\section{Course}

He has been followed for 3 years and there has been no progression of the weakness or involvement of other limbs.

\section{General comments and other negative investigations}

In each case a detailed sensory examination including estimation of vibration thresholds on fingers and toes, joint position, light touch, pin- prick and temperature were normal. None of the patients had Horner's syndrome. Normal sensory nerve action potentials were obtained from the median and ulnar nerves bilaterally in every case.

The following investigations were normal: CPK (except Case 2, ID), VDRL, protein immunoelectrophoresis, calcium phosphorous and alkaline phosphatase, $\mathrm{CBC}$.

None of the patients had a family history of neuromuscular disease. Three of the five had definitely had polio vaccination in childhood. There was no history of electric shock, exposure to lead or to a viral illness. None of the patients had had a rash. None of the patients had had major trauma. Two had practiced weight lifting or Kung Fu. In every case the dominant upper limb was involved first.

\section{Discussion}

A number of conditions have to be considered when a young patient presents with weakness and wasting of a distal upper extremity and structural lesions of the cord, roots and plexus have been excluded. Weakness from "brachial neuritis" 20 or herpes zoster ${ }^{21}$ is usually abrupt in onset and not progressive.

The distal myopathy described by Wellander ${ }^{22}$ has a later onset (mean 47 years) and is dominantly inherited. The weakness affects the finger extensors and the small hand muscles but there is also weakness of the distal muscles of the lower limbs. A recessive or sporadic form does have an earlier onset (19-33 years) but the weakness initially involves the intrinsic foot muscles and only rarely involves the hands. The CPK may be considerably raised $(5000 \mathrm{u} / \mathrm{L})$. In both of these conditions the motor unit action potentials are abundant but have brief durations and small amplitudes. 23

Distal weakness of neurogenic origin known as "distal spinal muscular atrophy" or "distal hereditary motor neuropathy" (which may be dominant or recessive) usually begins in the first decade. The initial weakness involves the small muscles of the feet and the anterior tibial compartments. Pes cavus and scoliosis are common. Weakness of the distal muscles of the upper limbs occurs in some cases. ${ }^{24}$ Harding et al 25 described "chronic asymmetrical spinal muscular atrophy". These patients had weakness and wasting in one limb either proximally or distally which spread, over 20 years, to affect all four limbs. The average age of onset was 32 years. These authors considered this to be different from monomelic atrophy (although two of their cases had weakness restricted to the hand and forearm muscles bilaterally which began before the age of 25 years). Hereditary sensory motor neuropathy (type II) also begins in the lower limbs ${ }^{26}$ is associated with sensory abnormalities and reduced or absent sensory nerve action potentials.

Focal demyelinating neuropathy 27 can also result in focal weakness which progresses and then appears to arrest. Nerve conduction and $f$ wave studies should provide evidence for focal demyelination. Slowly progressive weakness in children and young adults, particularly in the distribution of the posterior interosseous nerve or radial nerve, has resulted from localized proliferation of perineurium. ${ }^{28}$

The most difficult distinction is from motoneuron disease (at least until the lack of progression becomes evident). Our observations suggest that the transition between clearly involved muscles (for example extensor digitorum communis) and adjacent, clinically normal, muscles (for example brachioradialis) is more abrupt in monomelic amyotrophy whereas the abnormalities may be graded more gradually in motoneuron disease. 
All our patients were young men (aged 14 to 19 at the onset of their symptoms) who presented with distal weakness of one upper limb. Clinically the weakness affected the small hand muscles and the forearm flexors and extensors and triceps but spared the brachioradailis and extensor carpi radialis thus appearing to involve the $\mathrm{C} 7, \mathrm{C} 8, \mathrm{~T} 1$ segmental levels. All five progressed for 1 to 3 years (mean 1.4 years) and then arrested. The weakness remained predominantly unilateral except in one patient in whom both upper limbs became equally involved. There was no sensory loss and there were no long tract signs. The sensory and motor nerve conduction velocities were normal. The amplitudes of the muscle compound action potentials of distal muscles were some times surprisingly large in spite of clinical wasting. EMG showed a loss of motor units and large motor unit action potentials in weak muscles. Definite neurogenic changes were detected in distal muscles of the "uninvolved" upper limb (see Table 1) and in the clinically normal proximal muscles of the involved upper limb but no abnormalities were detected in lower limb muscles. The CT myelogram showed unilateral flattening of the cord which appears to be a characteristic of this condition. ${ }^{6}$ The MRI scan helped to exclude central cord lesions but did not demonstrate the atrophy of cord as well as the CT myelogram. The other investigations were normal except for a slight increase in CPK in one patient.

Our cases would appear to be examples of the condition described by Hirayama et al. ${ }^{7}$

Pathological data are available on only one case. ${ }^{7}$ This man had developed weakness and wasting of the left hand at the age of 15 years which had progressed for one year and then stabilized (a brother had developed similar weakness of the right hand aged 13 which progressed for 6 months). At age 35 he had noted slight atrophy of the right first dorsal interosseous and the definitive investigations were carried out at this time. There was weakness and wasting of the left forearm and hand muscles (sparing brachioradialis). Nerve conduction velocities were normal. EMG showed neurogenic changes in the atrophied muscles and these were confirmed by biopsy of the left flexor carpi ulnaris. The myelogram showed atrophy of the cord. At the age of 38 he developed a squamous cell carcinoma of the mediastinum and died of cerebral metastases.

At autopsy the spinal cord was flattened and the anterior roots thinned at C6-T1. There was shrinkage of the anterior horns particularly at C7-8 with loss of both large and small cells and degenerative changes in the remainder. There was slight thickening of the arachnoid on the anterior surface of the cord particularly around the rootlets. There were no macrophages, no vascular proliferation and the posterior horns and white matter were normal. There were no cystic changes. In the brachial plexus there was some loss of nerve fibres in the C8 trunk and loss of nerve cells in the inferior cervical sympathetic ganglion. The authors considered that these changes were unlike those of motoneuron disease, vasculitis, polio or trauma but concluded from the distribution that the changes "still seem to suggest a circulatory insufficiency in the lower cord as the most likely pathogenesis".

Although the majority of cases reported in the literature are from Japan and India the condition may be as common in North America.

\section{ACKNOWLEDGEMENTS}

We thank G. Trogadis for technical assistance with the electrophysiological studies and M. Cairoli for preparing the manuscript.

\section{REFERENCES}

1. Hirayama K, Toyokura Y, Tsubaki T. Juvenile muscular atrophy of unilateral upper extremity. Pyschiat Neurol Jap 1959; 61: 2190 . 2197.

2. Hirayama K, Tsubaki T, Toyokura $Y$, et al. Juvenile muscular atrophy of unilateral upper extremity. Neurology 1963; 13:373-380.

3. Gourie-Devi M, Suresh TG, Shankar SK. Monomelic amyotrophy. Arch Neurology 1984; 41 : 388-394.

4. Sobue I, Saito N, Iida M, et al. Juvenile type of distal and segemental muscular atrophy of upper extremities. Ann Neurol 1978; 3: 429-432.

5. Adornato BT, Engel WK, Kucera J, et al. Benign focal amyotrophy. Neurology 1978; 28: 399

6. Metcalf JC Jr, Wood JB, Bertorini TE. Benign focal amyotrophy; Metrizamide CT evidence of cord atrophy. Case report. Muscle and Nerve 1987; 10(4): 338-345.

7. Hirayama K, Tomonaga M, Kitano K, et al. Focal cervical poliopathy causing juvenile muscular atrophy of distal upper extremity: a pathological study. J Neurol Neurosurg Psychiatry 1987; 50: 285-290.

8. Amir D, Magora A, Vatine JJ. Proximal monomelic amyotrophy of the upper limb. Arch Phys Med Rehabil 1987; 68: 450-451.

9. Riggs JE, Schochet SS, Gutmann L. Benign focal amyotrophy. Arch Neurol 1984; 41: 678-679.

10. Hirayama K. Juvenile non-progressive muscular atrophy localized in the hand and forearm. Clin Neurol (Tokyo) 1972; 12: 313324.

11. Singh N, Sachdev KK, Susheela AK. Juvenile muscular atrophy localized to arm. Arch Neurol 1980; 37; 297-299.

12. Tan CT. Juvenile muscular atrophy of distal upper extremities. J Neurol Neurosurg Psychiatry 1985; 48: 285-286.

13. O'Sullivan DJ, McLeod JG. Distal chronic spinal muscular atrophy involving the hands. J Neurol Neurosurg Psychiatry 1978; 41: 653-658.

14. Compernolle $\mathrm{T}$. A case of juvenile muscular atrophy confined to one upper limb. Eur Neurol 1973; 10: 237-242.

15. De Visser $M$, Ongerboer de Visser BW, Verbeerten B. Electromyographic and computed tomographic findings in 5 patients with monomelic spinal muscular atrophy. Eur Neurol 1988; 28: 135-138.

16. Pilgaard S. Unilateral juvenile muscular atrophy of upper limbs. Acta Orthop Scand 1968; 39: 327-331.

17. Kimura J. Electrodiagnosis in diseases of nerve and muscle: principles and practice. Philadelphia: F A Davis 1983.

18. Shahani BT, Halpern JJ, Boulu P, et al. Sympathetic skin response - a method of assessing unmyelinated axon dysfunction in peripheral neuropathies. J Neurol Neurosurg Psychiatry 1984; 47: 536-542.

19. Stalberg E, Trontelj JV. Single fibre electromyography. Old Woking Miravalle Press 1979.

20. Tsairis $P$, Dyck PJ, Mulder DW. Natural history of brachial plexux neuropathy. Arch Neurol 1972; 27: 109-117.

21. Thomas JE, Howard FM. Segmental zoster paresis - a disease profile. Neurology 1972; 22: 459-466.

22. Wellander L. Myopathia distalis tarda hereditaria. Acta Med Scand 1951; (Suppl 265) 141: 1. 
23. Markesberry WR, Griggs RC. Distal myopathies. In: Engel AG and Banker BQ, eds. Myology. New York: McGraw Hill 1986; 13131325.

24. Harding AE. Inherited neuronal atrophy and degeneration predominantly of lower motor neurons. In: Dyck DJ, Thomas PK, Lambert EH, Burge R, eds. Peripheral Neuropathy. Philadelphia: WB Saunders $1984 ; 1537-1556$.

25. Harding AE, Bradbury PG, Murray NMF. Chronic asymmetrical spinal muscular atrophy. J Neurol Sci 1983; 59: 69-83.
26. Dyck PJ. Inherited neuronal degeneration and atrophy affecting peripheral motor sensory and autonomic axons. In: Dyck PJ, Thomas PK, Lambert LH, Burge R, eds. Peripheral Neuropathies. Philadelphia: WB Saunders 1984; 1060-1655.

27. Lewis RA, Sumner AJ, Brown MJ, et al. Multifocal demyelinating neuropathy with persistant conduction block. Neurology 1982; 32: 958-964.

28. Tranmer BI, Bilbao JM, Hudson AR. Perineurioma: a benign peripheral nerve tumor. Neurosurgery 1986; 19: 134-138. 